\title{
Biomechanics of Subcutaneous Locked Plating vs Burke Plate and External Fixator for Comminuted Distal Radius Fractures
}

\section{Andrew Pytiak}

Detroit Medical Center

Xin Jin

Wayne State University

Zlatan Cizmic

St. John Providence Hospital

\section{Austen Washington}

Detroit Medical Center https://orcid.org/0000-0002-5960-7777

Rahul Vaidya ( $\nabla$ rahvaidya2012@gmail.com)

Detroit Medical Center https://orcid.org/0000-0001-6870-6091

Research article

Keywords: Internal, fixation, External, subcutaneous, comminuted, distal, radius, fracture, Burke plate

Posted Date: October 21st, 2020

DOl: https://doi.org/10.21203/rs.3.rs-94004/v1

License: (c) (1) This work is licensed under a Creative Commons Attribution 4.0 International License. Read Full License 


\section{Abstract}

Background: External fixators that span the wrist have been the historical norm in treating distal radius fractures. We have modified a dorsal distraction approach by using a subcutaneously applied locked bridge plate through 2 small incisions superficial to the extensor tendons and outside the extensor compartment. The purpose of this study was to biomechanically evaluate this modified method of fixation for comminuted distal radius fractures in comparison with two established constructs.

Methods: Matched cadaver specimens were used to model an AO Type 23-C3 distal radius fracture. Biochemical testing for stiffness during axial compressive loading was done on three constructs: a conventional Burke distraction plate, the subcutaneous internal fixation plating technique and an external fixator. All specimens were cyclically loaded for 3000 cycles and then retested.

Results: The modified construct was found to be stiffer than the external fixator $(p=0.013)$. When compared to the Burke plate, the modified construct was significantly less stiff before axial cycling $(p=0.025)$. However, the difference was not maintained after cycling and the post-axial loading stiffness difference was non-significant $(p=0.456)$.

Conclusion: Our data demonstrate the biomechanical integrity of the subcutaneous plating technique for the fixation of comminuted distal radius fractures. It is stiffer than an external fixator and has the theoretical advantage of avoiding pin-tract infections. In addition, it is subcutaneous, and not a cumbersome external construct. Our construct is minimally invasive and does not violate the dorsal extensor compartments allowing movement of the fingers while the construct is in place.

\section{Background}

Distal radius fractures are the second most common reason for emergency department treatment, with a concurrent 13-fold increase in open reduction and plate fixation. Comminuted fractures of the distal radius have proven particularly difficult to reduce and stabilize ${ }^{1-4}$.

While still used for most severely comminuted intraarticular fractures, external fixators can have inadequate maintenance of reduction as well as complications associated with pin tract infection, superficial radial nerve neuropathy, pin loosening, and stiffness ${ }^{5-9}$. The complications associated with external fixation of highly comminuted and multiple injury radial fractures has left these techniques as amenable treatment options for low-demand patients ${ }^{10}$.

Internal fixation with plating provides adequate stabilization without the complications of external fixators ${ }^{11,12}$. Burke and Singer first described the dorsal distraction plate which has been used by several authors for addressing severely comminuted fractures that are not amenable to traditional open reduction and internal fixation 11,13 . The distraction plate aims to reduce immobilization, increasing tensile strength and physical demand on ligaments, resulting in more effective stabilization and recovery

${ }^{3}$. This technique not only minimizes complications, but provides more construct stiffness than external 
fixation ${ }^{14}$. However, the distal radius spanning distraction plate has some associated morbidity, concerning adhesion and rupture of the extensor pollicis longus, nerve entrapment, and hardware failure ${ }^{15}$. In addition to these risks, studies have found a $10^{\circ}$ extensor lag ${ }^{11}$. Recently, Lewis et al. have found that conventional plating onto the 3rd metacarpal has a significant increase in adverse effects compared to insertion onto the 2 nd metacarpal ${ }^{16}$. We propose an adaptation of this distal radius spanning technique that places the plate subcutaneously, while staying superficial to the extensor compartment and plating to the 2nd metacarpal or 3rd metacarpal, thereby addressing the concerns of tendon damage, muscle disruption, and restricted finger movement. By doing so, reduction and stabilization is provided to a severely comminuted radial fracture without disrupting the muscle tendons; theoretically allowing improved retention of finger range of motion in the postoperative period, ease of insertion and removal, and minimal soft tissue or compartment disruption. While there has been biomechanical and clinical evidence to support the superiority of plating to external fixators, biomechanical testing of a subcutaneous plate has not been published to the authors' knowledge at the time of this article ${ }^{17}$.

The modified Burke plate offers the potential to provide quicker recovery of finger range of motion, decreased risk of infection, minimal soft tissue damage upon insertion and removal, and a socially less visible scar. The purpose of this study was to evaluate the biomechanical aspects of the modified internal fixation plate for comminuted distal radius fractures, in comparison with two established constructs that are commonly used in similar radial fractures. We hypothesize that our novel subcutaneous locked bridge plate will be stiffer than the external fixator device, and less stiff than the Burke plate.

\section{Materials And Methods}

IRB approval was obtained from our home institution prior to beginning our investigation. Three sets of match paired fresh frozen cadavers were obtained for testing. Three constructs were tested: a $3.5 \mathrm{~mm} 14$ hole plate (Synthes, PA) placed using the subcutaneous plating technique, a $3.5 \mathrm{~mm}$ plate 14 hole plate (Synthes, PA) using the Burke internal distraction technique, and a standard external fixation construct which spanned the distal radius. Each construct was tested on three matched pairs of radii. Each technique was first assembled on the respective radius, which was followed by a $1 \mathrm{~cm}$ transverse osteotomy of the distal radius in order to create a defect in the distal radius to simulate a severely comminuted fracture. This approach was aimed at eliminating any bias between fixation, and creating an ideal comparison available for biomechanical testing.

Biomechanical comparisons were evaluated for axial compression loading, cantilever bending in volar-todorsal, dorsal-to-volar, ulnar-to-radial, and radial-to-ulnar directions as well as torsion loading. A materials testing system (Instron 8500, Norwood MA) was used to test each specimen under load control. Specimens were all cyclically loaded at $50 \mathrm{~N}$. Torsional loading was performed at $0.5 \mathrm{~N} / \mathrm{m}$. 3000 cycles were applied in each direction to every construct. Specimens were tested in the following order: axial compression, volar-to-dorsal cantilever bending, dorsal-to-volar cantilever bending, radial-to-ulnar cantilever bending, ulnar-to-radial cantilever bending, and torsional loading. Displacement was measured in millimeters with respect to load for each specimen. The specimens were mounted on a custom jig after 
being potted in polymethylmethacrylate (Fig. 1). Following potting and set up in the custom jig, axial loading was applied on the distal aspect of the second metacarpal head. For the point of bending, torque was directly applied through a pin used for stabilization of the second metacarpal into the custom jig.

\section{Surgical Techniques}

The internal distraction plate was placed as previously described by Burke and Singer ${ }^{13}$. Dissection was performed over the third compartment, and the extensor pollicis longus was mobilized to expose the bone fragment in which the defect would be created. Dissection was carried distally over the 2 nd metacarpal to provide adequate comparison with the subcutaneous infix plate. The extensor tendon was identified and protected while exposing the $2 \mathrm{nd}$ metacarpal. The $3.5 \mathrm{~mm}, 14$ hole Synthes plate (was then aligned from the dorsal surface of the distal radius, just ulnar to the extensor carpi radialis longus and brevis, to the 2nd metacarpal, deep to the extensor tendons as described by Burke and Singer ${ }^{11,13}$. The plate was then fixed both proximally and distally with three non-locking cortical screws on either side of the osteotomy site.

The second construct that was tested was the subcutaneous infix distal radius spanning technique. The infix technique also involved the use of a 14 hole, $3.5 \mathrm{~mm}$ locking plate. Two small incisions on the dorsal aspect of the arm, the first between the 2nd and 3rd metacarpal and the second overlying the distal third of the radius (Fig. 2). Blunt dissection was performed connecting the two incisions while staying superficial to the extensor tendons and outside the third and fourth extensor compartments. The plate was then slid subcutaneously from the proximal incision to the distal incision. The plate was fixed subcutaneously on the dorsal aspect of the forearm spanning from the radius to the second metacarpal with 3 locking screws on either side of the osteotomy site. In order to ensure similar testing conditions, all subcutaneous plates were placed $15 \mathrm{~mm}$ off of the bone. An example of a $49 \mathrm{y}$.o. female who fell on her right outstretched hand and underwent a subcutaneous distraction plate is demonstrated in Fig. 3 preop comminuted intra-articular distal radius fracture, Interop x-rays and clinical pictures Fig. 4, post op x-rays Fig. 5, 1 year Fig. $6 a$ and 5 year post op x-rays Fig. $6 \mathrm{~b}$.

A small external fixator (Synthes, PA) was the third construct that was tested. Percutaneous pins were inserted through the second and third metacarpal bones and the radius in a transverse direction. A lowtorque power drill was used to insert the Steinmann pins. The distal pins were placed transverse and perpendicular to each other at the bases of the second and third metacarpals. This was followed by drilling parallel pins to the distal radius approximately three to five centimeters proximal to the planned osteotomy site ${ }^{3}$.

Once each construct was secured, a transverse osteotomy was performed on the distal radius to create a $1 \mathrm{~cm}$ defect to simulate a badly comminuted distal radius fracture. All specimens, with fixed constructs already attached, were potted and inserted into a custom jig prior to performing the osteotomy.

\section{Statistical Analysis}


Mann-Whitney U comparisons were performed in order to compare pre-axial to post-axial loading conditions. Nonparametric analysis was chosen given the small sample size. Alpha value was set at 0.05 ; assumption was made of superiority to external fixation, and non-inferiority in comparison with the Burke plate. Nonparametric and descriptive analyses were performed with SAS 9.3 (SAS Institute Inc, Cary, NC).

\section{Results}

The Burke plate was found to have the following average post-cyclic loading stiffnesses: $299.93 \mathrm{~N} / \mathrm{m}$ during axial loading, $4.36 \mathrm{~N} / \mathrm{m}$ during radial-to-ulnar bending, $4.25 \mathrm{~N} / \mathrm{m}$ during ulnar-to-radial, $1.99 \mathrm{~N} / \mathrm{m}$ dorsal-to-volar bending, $1.39 \mathrm{~N} / \mathrm{m}$ during volar-to-dorsal bending, and $0.03 \mathrm{~N} \mathrm{~m} / \mathrm{m}$ during torsional loading. No failure was noted during cyclic loading.

The custom subcutaneous plate was found to have the following average post-cyclic loading stiffnesses: $217.83 \mathrm{~N} / \mathrm{m}$ during axial loading, $3.25 \mathrm{~N} / \mathrm{m}$ during radial-to-ulnar bending, $3.25 \mathrm{~N} / \mathrm{m}$ during ulnar-toradial, $1.21 \mathrm{~N} / \mathrm{m}$ dorsal-to-volar bending, $1.02 \mathrm{~N} / \mathrm{m}$ during volar-to-dorsal bending, and $0.03 \mathrm{~N} \mathrm{~m} / \mathrm{m}$ during torsional loading. No failure was noted during cyclic loading.

The external fixation construct was found to have the following average post-cyclic loading stiffnesses: $49.33 \mathrm{~N} / \mathrm{m}$ during axial loading, $1.63 \mathrm{~N} / \mathrm{m}$ during radial-to-ulnar bending, $1.83 \mathrm{~N} / \mathrm{m}$ during ulnar-to-radial, $1.91 \mathrm{~N} / \mathrm{m}$ dorsal-to-volar bending, $1.77 \mathrm{~N} / \mathrm{m}$ during volar-to-dorsal bending, and $0.06 \mathrm{~N} \mathrm{~m} / \mathrm{m}$ during torsional loading. No failure was noted during cyclic loading.

In terms of axial stiffness, the modified subcutaneous construct was found to be more stiff than the external fixator, both before and after load cycling ( $p=0.013$ for both).

When compared to the Burke plate, the modified subcutaneous construct was significantly less stiff before axial cycling $(p=0.025)$. However, the difference in stiffness between the Burke plate and the subcutaneous in-fix plate was not maintained at the end of cyclic loading $(p=0.456)$.

\section{Discussion}

Open reduction and internal fixation has become the predominant mode of fracture fixation of the distal radius ${ }^{18-20}$. Plating has reduced the rate of infections and provided patients the ability to bear weight on the extremity, but comes with the risk of tendon compartment entrapment or tendon lag ${ }^{11,16}$. Recently, Lauder et al conducted a retrospective study that analyzed the functional outcomes of dorsal-spanning bridge plating. They found that grip strength was $86 \%$ and extension torque was $78 \%$ when compared to the uninjured contralateral wrist. Dominant and nondominant wrist injuries were identified with nearly complete recovery of dominant-sided grip (95\%) and extension (96\%), and non-dominant-sided grip (79\%) and extension (65\%) strength. There were only 2 cases of postoperative surgical site pain with no cases of infection, tendonitis, or tendon rupture ${ }^{21}$. However, this is not to say that dorsal-spanning bridge plating lacks complications. Such complications can be separated into minor (wound healing and hardware failure without loss of reduction) and major complications (malunion, nonunion requiring 
surgery, wound complications/unplanned surgery, deep infection, extensor tendon adhesions/tenolysis, EPL rupture requiring and EIP transfer) ${ }^{22}$. Several studies have demonstrated clinical complications with the use of the conventional distraction plate as well. Hanel et al. reported one extensor carpi radialis longus rupture with hardware failure in their study of 52 patients ${ }^{22}$. Ruch et al. had 3 patients with extensor lags of $10^{\circ}$ from their 22 patients with reported mean Disabilities of the Arm, Shoulder and Hand (DASH) score of 11.5 points at final follow-up ${ }^{11}$. Richard et al. reviewed distraction plating of comminuted distal radius fractures in 33 elderly patients and reported complications including digital stiffness, required tenolysis at the time of plate removal, superficial radial neuritis, and chronic regional pain syndrome ${ }^{23}$. Another study on the dorsal-bridge plating technique identified complications including: tendon rupture, tenosynovitis, reoperation, and $25 \%$ collapse ${ }^{24}$.

There has also been controversy in the specific technical approaches between volar or dorsal plating. Some authors prefer a volar plate to avoid the risk of extensor tendon damage, while other authors believe that a volar approach provides better biomechanical outcomes ${ }^{25-35}$. Rein et al. described 2 of 14 patients with dorsal plating who experienced extensor tendon irritation, 2 patients with fragment displacement and 3 cases of nerve irritation. This is in comparison to 12 of 14 patients that had no complications with the volar approach. However, they also point out that novel dorsal plates and modified techniques could overcome these issues ${ }^{34}$. Similarly, Henry et al. described the advantages of volar plating as having a socially less visible scar and the ability to support immediate functional loading of the hand, wrist, and forearm in both rehabilitation and daily activities. It was also noted that with increasing fracture complexity that restoration of volar tilt becomes increasingly difficult without the use of a device to achieve the lift maneuver ${ }^{29}$.

Radiologic, clinical, and biomechanical studies have been performed advocating the superiority of dorsal plating over volar plating. Letsch et al. provided radiologic evidence that palmar plates (1.7 points) had a significantly lower result than patients with a dorsal plate $(1.0$ points, $p<0.05)$. In such studies, locked or non-locked dorsal constructs were more than 2 times stiffer than volar constructs. With regards to functional outcome, there was a strong tendency for better outcomes with dorsal plating (3.0 points) compared with palmar plating (4.1 points); however, these findings were not significant ${ }^{36}$. A biomechanical study by Trease et al. proved that while not statistically significant, the failure strength of dorsal constructs was $53 \%$ higher than that of volar constructs ${ }^{37}$. While volar versus dorsal plating remains an ongoing issue, the novel subcutaneous plate provides stiffness as good as the conventional dorsal-spanning bridge plate, therefore handling stiffness similar to volar plates.

The modified subcutaneous construct aims to overcome common complications of badly comminuted distal radius fractures via multiple modifications to current techniques. Lewis et al. first provided evidence that plating to the second metacarpal did not result in tendon entrapment, but plating to the third metacarpal resulted in six tendon entrapments in six samples ${ }^{16}$. With respect to Lewis' data for the insertion of distal plating sites, the modified construct was placed to the second metacarpal to minimize tendon entrapment. In addition, by staying superficial to the extensor compartment, the above mentioned 
complications should theoretically be marginal due to minimal soft tissue disruption and violation of the third and fourth extensor compartments, as well as bypassing possible nerve injury. The data from the current study suggests that the subcutaneous internal fixator plate provides adequate structural support similar to the traditional Burke approach after cycling and is both stiffer and stronger than an external fixator.

In the current study, we tested the axial and torsional durability of external fixation, the Burke plate, and subcutaneous plating. The results demonstrate the biomechanical integrity of our modified construct for the fixation of comminuted distal radius fractures. It is stiffer than an external fixator, and has the theoretical advantage of avoiding pin-tract infections. In addition, it is subcutaneous and not as cumbersome as the external construct. While not as stiff as the Burke plate, our construct is minimally invasive, easier to remove, and does not violate the dorsal extensor compartments allowing movement of the fingers while the construct is in place. The results of this study, in addition to the theoretical circumvention of well-known complications, support dorsal subcutaneous plating as an alternative for highly comminuted distal radius fractures.

While the current study portrays biomechanical loading as good as the conventional plate and better stiffness than the external fixator, there are limitations to the current study as well. A primary limitation of this study is the relatively low number of specimens used. However, nonparametric statistical analyses are less sensitive to sample size issues, and statistical significance was still achieved despite the limited number of specimens used. This study was performed in cadaveric specimens, therefore, the effects of osteogenesis on the tested constructs could not be evaluated and cyclic data should be interpreted with caution. Finally, while age-matched specimens allowed for comparison of two biologically similar samples, the clinical significance of these results cannot be determined without further study.

We accept the alternative hypothesis that the modified subcutaneous construct is superior to external fixation in terms of stiffness both pre- and post-axial load cycling. We found that the Burke plate was superior in stiffness before axial cycling, but the difference does not reach significance after axial cycling, suggesting that the modified plate should be as resilient as the Burke plate in actual use. We recognize the small sample size may have affected power to detect a post-cycling difference, but on the basis of marked superiority to external fixation and reduced invasiveness for installation, we have identified an important alternative technique for the fixation of severely comminuted distal radius fractures. Future studies will focus on clinical results of the subcutaneous infix plating technique.

\section{Conclusions}

The modified subcutaneous internal fixator device provides superior stiffness results as compared to the external fixator in both pre and post axial cycling. The construct is less invasive than the external fixator while having the potential to limit common associated infections. In this data series the subcutaneous internal fixator device exhibited significantly inferior stiffness pre axial cycling and non significant inferior stiffness post axial cycling as compared to the Burke plate. 


\section{Abbreviations}

Infix: Internal fixation

\section{Declarations}

\section{Ethics approval and consent to participate}

Study was submitted to and approved by the Wayne State University Institutional Review Board

\section{Consent for publication}

Not Applicable

\section{Availability of data and materials}

The datasets used and/or analysed during the current study are available from the corresponding author on reasonable request.

\section{Competing interests}

The author(s) declare(s) that they have no competing interests.

\section{Funding}

Not Applicable

\section{Authors' contributions}

$\mathrm{RV}, \mathrm{AP}, \mathrm{CZ}$, and $\mathrm{XJ}$ were involved in all surgical procedures, compiling data, statistical analyses, and manuscript write-up. AW reviewed and edited the manuscript. All authors have seen and confirmed the manuscript for final approval before submission.

\section{Acknowledgements}

Not Applicable

\section{References}


1. Chung KC, and Spilson SV. The frequency and epidemiology of hand and forearm fractures in the United States. J Hand Surg Am 2001; 26A:908-915.

2. Chung KC, Shauver MJ, Yin H. The relationship between ASSH membership and the treatment of distal radius fracture in the United States Medicare population. J Hand Surg 2011;36A:1288-1293.

3. Cooney WP 3rd, Linscheid RL, Dobyns JH. External pin fixation for unstable Colles' fractures. J Bone Joint Surg Am 1979;6A:840-845.

4. Green DP. Pins and plaster treatment of comminuted fractures of the distal end of the radius. J Bone Joint Surg Am. 1975;57(3):304-10.

5. Ahlborg HG, Josefsson PO. Pin-tract complications in external fixation of fractures of the distal radius. Acta Orthop Scand. 1999;70(2):116-118

6. Parameswaran AD, Roberts CS, Seligson D, et al. Pin tract infection with contemporary external fixation: how much of a problem? J Orthop Trauma. 2003;17(3):503-507.

7. Weber SC, Szabo RM. Severely comminuted distal radial fracture as an unsolved problem: complications associated with external fixation and pins and plaster techniques. J Hand Surg. 1986;11(2):157-165.

8. Wild JJ Jr, Hanson GW, Bennett JB, et al. External fixation use in the management of massive upper extremity trauma. Clin Orthop Relat Res. 1982; 164:172-176.

9. Williksen JH, Husby T, Hellund JC, et al. External Fixation and Adjuvant Pins Versus Volar Locking Plate Fixation in Unstable Distal Radius Fractures: A Randomized, Controlled Study With a 5-Year Follow-Up. J Hand Surg Am. 2015 Jul;40(7):1333-40.

10. Skinner, Harry B. Current Diagnosis \& Treatment in Orthopedics. 5th ed. New York: Lange Medical /McGraw-Hill Medical Pub. Div., 2006.

11. Ruch DS, Gin TA, Yang CC, et al Use of a distraction plate for distal radial fractures with metaphyseal and diaphyseal comminution. J Bone Joint Surg Am 2005;87A;945-54.

12. Kreder HJ, Hanel DP, Agel J, et al. Indirect reduction and percutaneous fixation versus open reduction and internal fixation for displaced intra-articular fractures of the distal radius. J Bone Joint Surg $\mathrm{Br}$. 2005;6:829-836.

13. Burke EF, Singer RM. Treatment of comminuted distal radius with the use of an internal distraction plate. Tech Hand Up Extrem Surg. 1998;2:248-252.

14. Behrens F, Johnson WD, Koch TW, et al. Bending stiffness of unilateral and bilateral fixator frames. Clin Orthop Relat Res. 1983;178:103-110. 
15. Hanel DP, Lu TS, Weil WM. Bridge plating of distal radius fractures: the Harborview method. Clinical Orthop Relat Res. 2006;445;91-99.

16. Lewis S, Mostofi A, Stevanovic M, et al. Risk of tendon entrapment under a dorsal bridge plate in a distal radius fracture model. J Hand Surg Am. 2005;40(3):500-504.

17. Freeland $A E$, Luber $K T$. Biomechanics and biology of plate fixation of distal radius fractures. Hand Clin. 2005;21(3):329-39.

18. Cui Z, Pan J, Yu B, et al. Internal.versus external fixation for unstable distal radius fractures: an up-todate meta-analysis. Int Orthop. 2011;35(9):1333-1341.

19. Grewal R, Macdermid JC, King GJ, et al. Open reduction internal fixation versus percutaneous pinning with external fixation of distal radius fractures: a prospective, randomized clinical trial. J Hand Surg Am. 2011;36(12):1899-1906.

20. Wolf JC, Weil WM, Hanel DP, et al A biomechanic comparison of an internal radiocarpal-spanning 2.4-mm locking plate and external fixation in a model of distal radius fractures. J Hand Surg Am 2006;31(10)1578-1586.

21. Lauder A, Agnew S, Bakri K, et al. Functional outcomes following bridge plate fixation for distal radius fractures. J Hand Surg Am. $2015 ; 40$ (8):1554-1562.

22. Hanel DP, Ruhlman SD, Katolik LI, et al. Complications associated with distraction plate fixation of wrist fractures. Hand Clin. 2010;26(2):237-243.

23. Richard MJ, Katolik LI, Hanel DP, et al. Distraction plating for the treatment of highly comminuted distal radius fractures in elderly patients. J Hand Surg Am, 2012;37(5);948-956.

24. Ruch DS, Papadonikolakis A. Volar versus dorsal plating in the management of intra-articular distal radius fractures. J Hand Surg Am. 2006;31(1):9-16.

25. McCall TA, Conrad B, Badman B, et al. Volar versus dorsal fixed-angle fixation of dorsally unstable extra-articular distal radius fractures: a biomechanic study. J Hand Surg Am 2007;32(6):806-812.

26. Smith DW, Henry MH. Volar fixed angle plating of the distal radius. J Am Acad Orthop Surg 2005;13(1):28 -36.

27. Henry MH. Immediate mobilisation following corrective osteotomy of distal radius malunions with cancellous graft and volar fixed angle plates. J Hand Surg Eur 2007;32(1):88 -92.

28. Smith DW, Brou KE, Henry MH. Early active rehabilitation for operatively stabilized distal radius fractures. J Hand Ther 2004;17(1):43-49. 
29. Henry MH, Griggs SM, Levaro F. Volar approach to dorsal displaced fractures of the distal radius. Tech Hand Up Extrem Surg 2001;5(1):31- 41.

30. Osada D, Viegas SF, Shah MA, et al. Comparison of different distal radius dorsal and volar fracture fixation plates: a biomechanical study. J Hand Surg Am. 2003;28(1):94-104.

31. Osada D, Fujita S, Tamai K, et al. Biomechanics in uniaxial compression of three distal radius volar plates. J Hand Surg Am. 2004;29(3):446-451.

32. Leung $\mathrm{F}$, Zhu L, Ho H, et al. Palmar plate fixation of $\mathrm{AO}$ type $\mathrm{C} 2$ fracture of distal radius using a locking compression plate-a biomechanical study in a cadaveric model. J Hand Surg Br. 2003;28(3):263-266.

33. Liporace FA, Gupta S, Jeong GK, et al. A biomechanical comparison of a dorsal 3.5-mm T-plate and a volar fixed-angle plate in a model of dorsally unstable distal radius fractures. J Orthop Trauma 2005;19(3):187-91.

34. Rein S, Schikore H, Schneiders W, et al. Results of dorsal or volar plate fixation of AO type C3 distal radius fractures: a retrospective study. J Hand Surg Am. 2007;32(7):954-961.

35. Oshige T, Sakai A, Zenke Y, et al. A comparative study of clinical and radiologic outcomes of dorsally angulated, unstable distal radius fractures in elderly patients: intrafocal pinning versus volar locking plating. J Hand Surg Am. 2007; 32(9):1385-1392.

36. Letsch R, Infanger M, Schmidt J, et al. Surgical treatment of fractures of the distal radius with plates: a comparison of palmar and dorsal plate position. Arch Orthop Trauma Surg. 2003;123(7):333-339.

37. Trease C, Mclff T, Toby EB. Locking versus nonlocking T-plates for dorsal and volar fixation of dorsally comminuted distal radius fractures: a biomechanical study. J Hand Surg Am. 2005;30(4):756-763.

\section{Figures}



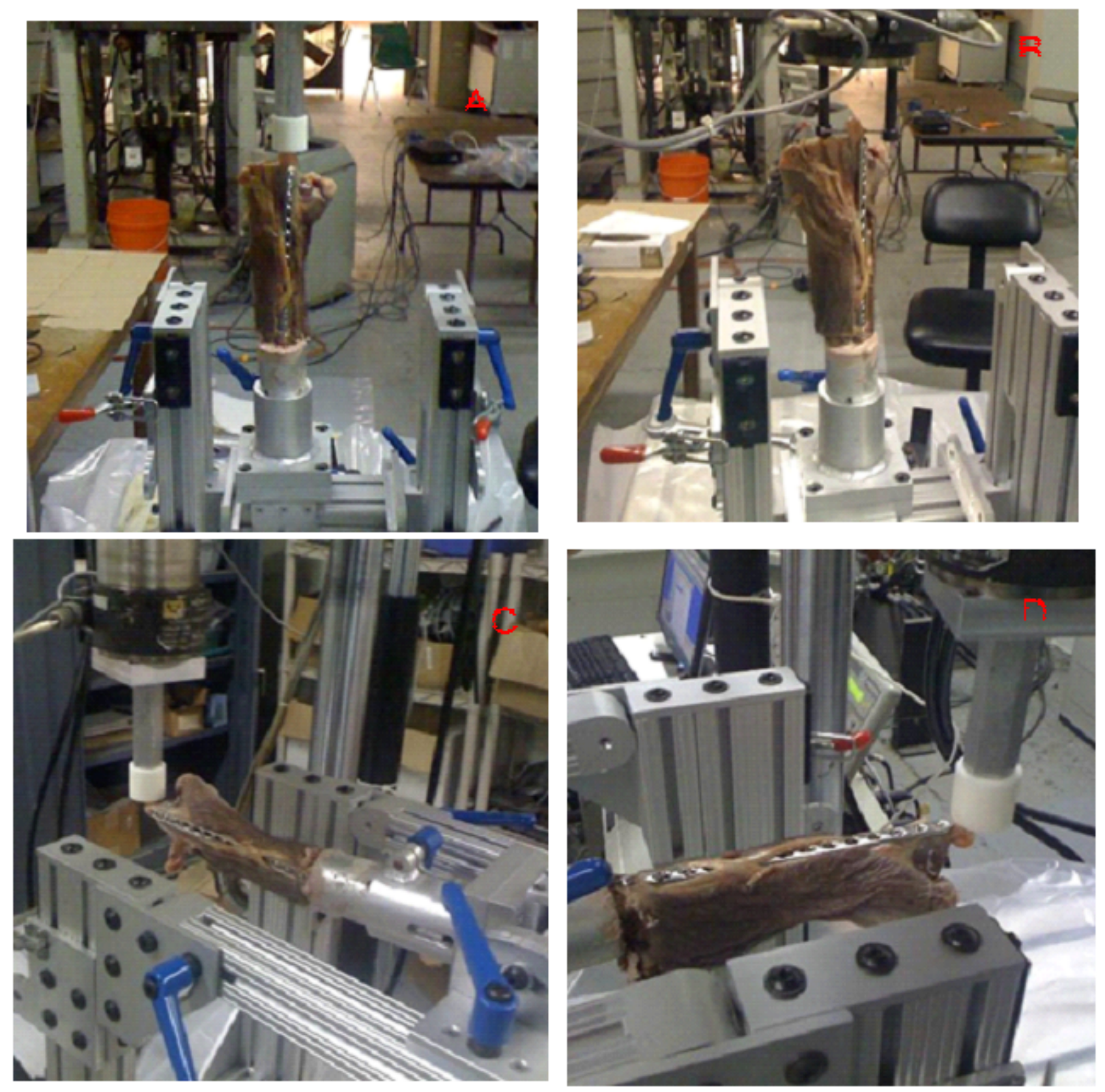

\section{Figure 1}

Testing positions and point of loading of the specimens within the materials testing machine for A) axial loading $\mathrm{B}$ ) torsional loading $\mathrm{C}$ ) radial to ulnar loading and D) dorsal to volar loading. 

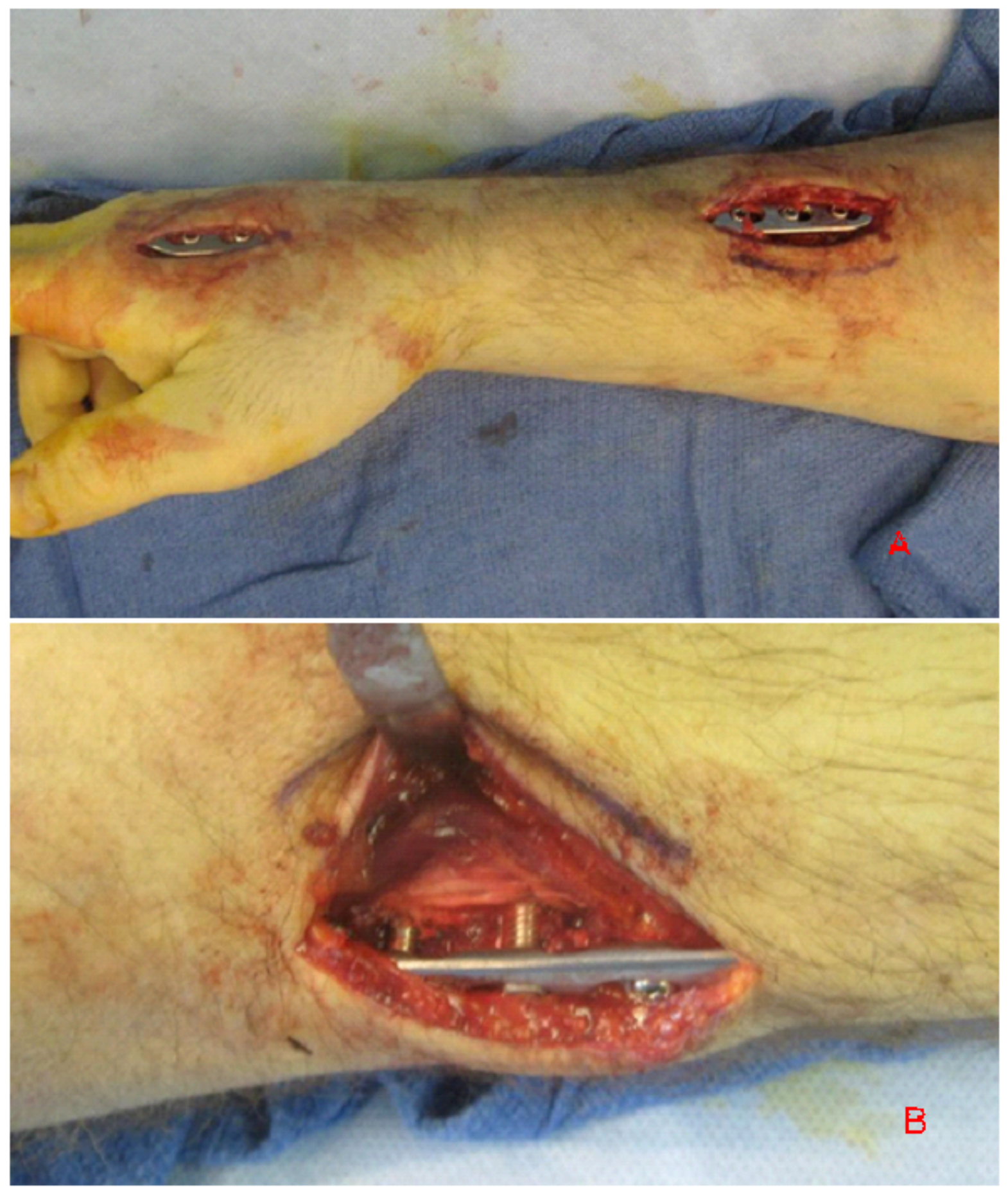

\section{Figure 2}

Photograph of one of the specimens demonstrating A) incision placements for subcutaneous in-fix plate fixation along the dorsal aspect of the forearm and B) a close-up of the proximal incision demonstrating its subcutaneous placement and suspension superficial to the fascia and extensor compartments. 


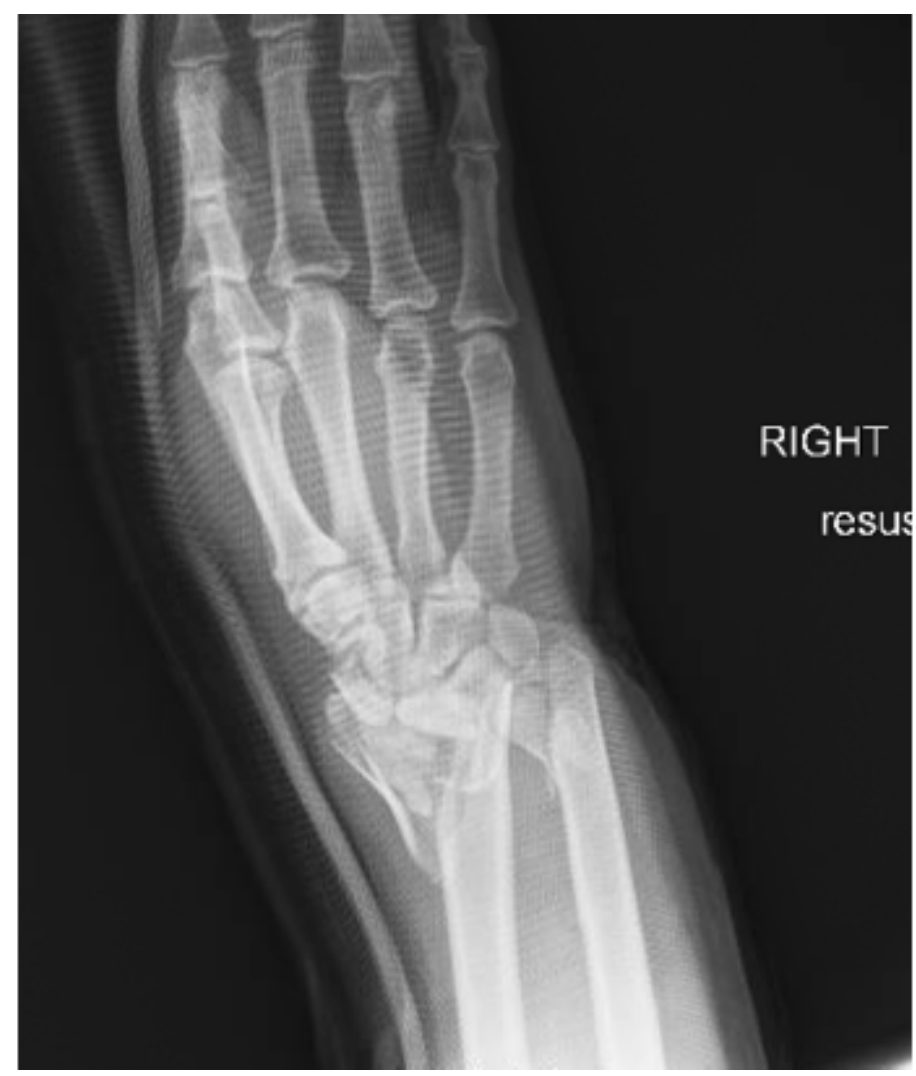

\section{Figure 3}

An example of a 49 y.o. female who fell on her right outstretched hand and underwent a subcutaneous distraction plate is demonstrated.

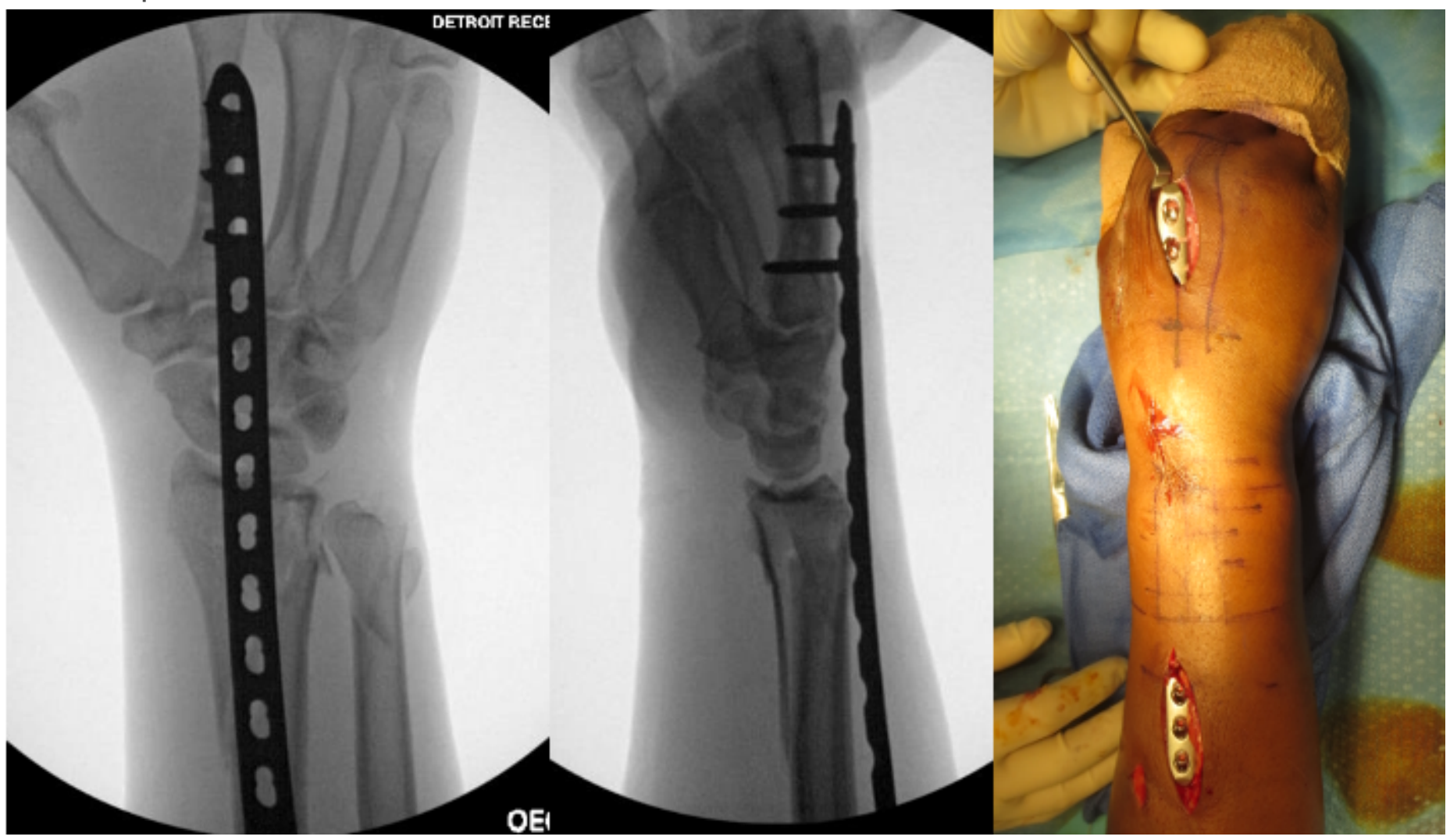

Figure 4 
Preop comminuted intra-articular distal radius fracture, Interop x-rays and clinical pictures,

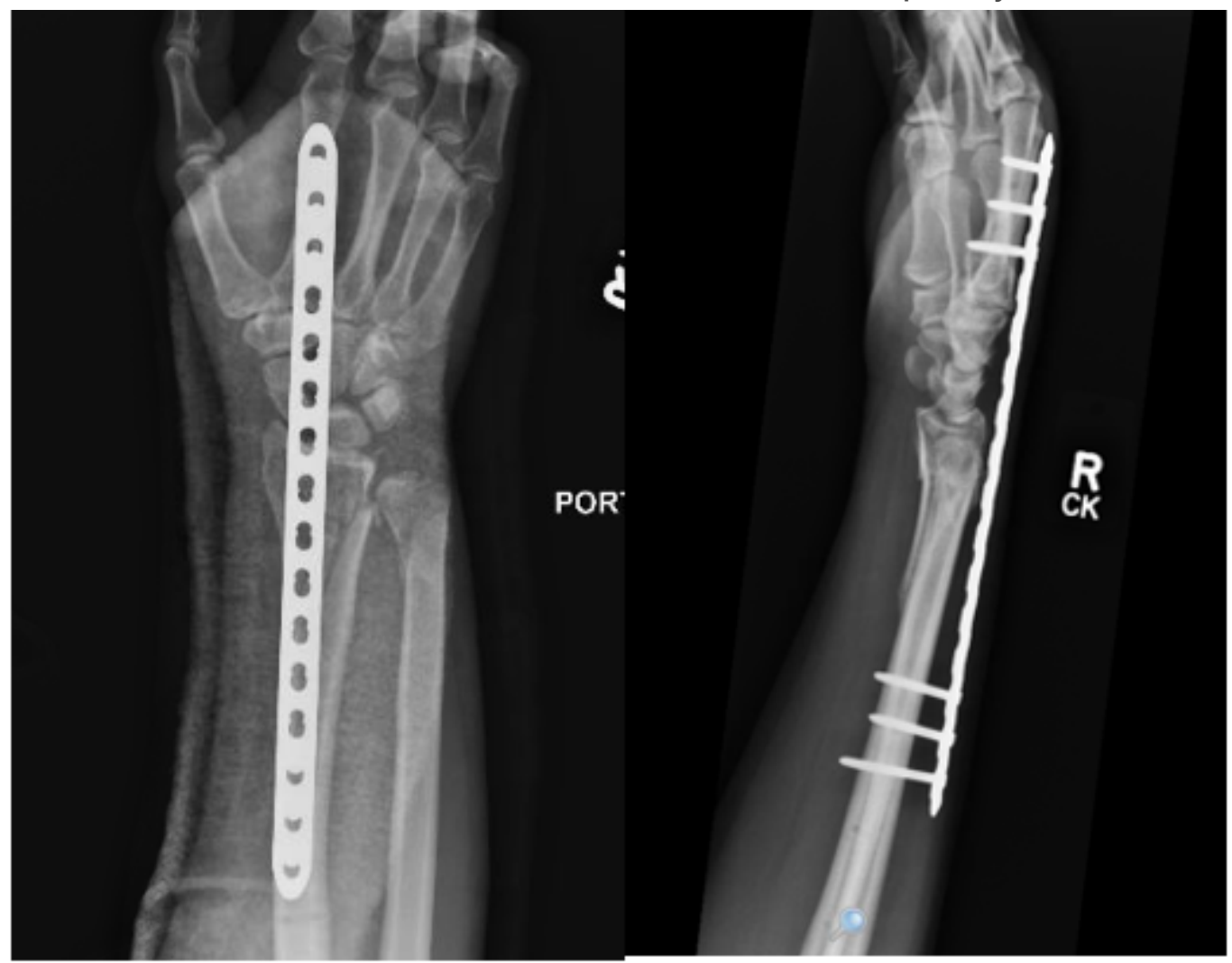

Figure 5

Preop comminuted intra-articular distal radius fracture, Interop x-rays and clinical pictures,
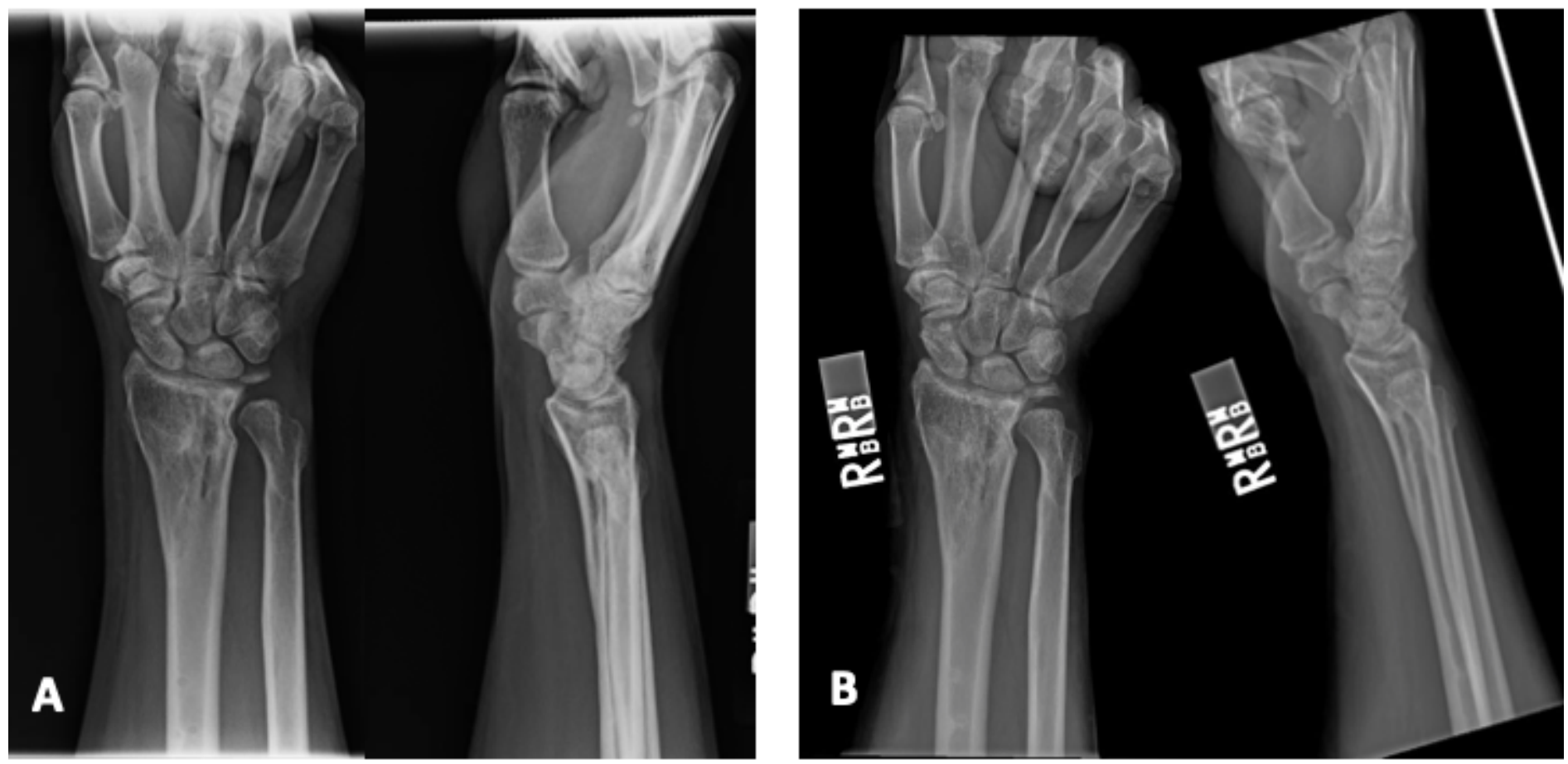

Figure 6 
1 year post op. Plate was removed at 3 months post op 5 year post op $x$-rays 